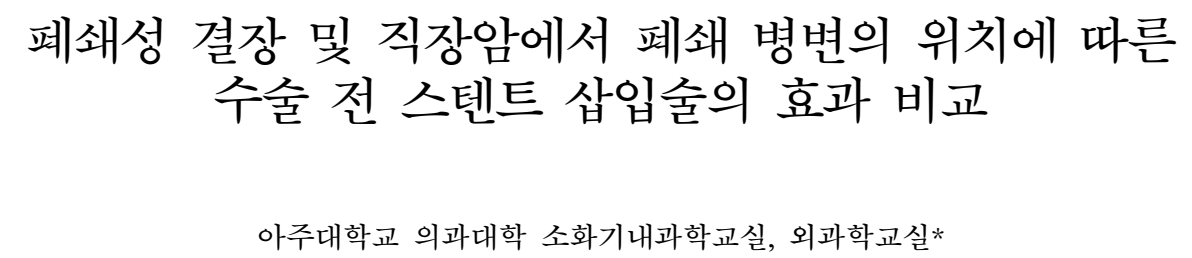

김종수 · 오승엽* · 서광욱* · 이명희 · 전수진 · 임현철 · 김진홍 · 이광재

\title{
Comparison of Effects of Preoperative Stenting for Obstructing Colorectal Cancers according to the Location of the Obstructing Lesion
}

Jong Su Kim, M.D., Seung Yeob Oh, M.D.*, Kwang Uk Seo, M.D.*, Meong Hee Lee, M.D., Su Jin Cheon, M.D., Heon Cheol Im, M.D., Jin Hong Kim, M.D., and Kwang Jae Lee, M.D.

Departments of Gastroenterology and Surgery*, Ajou University School of Medicine, Suwon, Korea

Background/Aims: With the development of self-expanding metallic stents, colonic obstruction can be relieved without the need for surgery. The results of preoperative placement of stents for malignant colorectal obstruction might be different according to the obstructing lesion. The objective of this study was to compare clinical improvement rates and operative results after preoperative placement of stents for malignant colorectal obstruction according to the location of the obstructing lesion. Methods: This is a retrospective study including 57 patients who underwent self-expanding metallic stent insertion for obstructing resectable colorectal cancers. Patients were classified into three groups according to the location of the lesion as follows: proximal to the sigmoid colon (Group A), sigmoid colon (Group B), and rectum (Group C). Results: The number of patients in A, B, and C groups was 13,22 , and 22, respectively. No significant differences in age, gender, stent type, and accompanying diseases among the three groups were observed. There were no significant differences in stent-related complications, clinical improvement rates, and one-stage resection rates among the three groups. The postoperative complications, the requirement rate of ICU care, the period of ICU stay, postoperative hospital stay, and hospital mortality did not significantly differ among the three groups. Conclusions: Clinical improvement rates and operative results after successful placement of stents for obstructing resectable colorectal cancers are not different according to the location of the obstructing lesion, suggesting that preoperative stenting for one-stage curative resection is useful, irrespective of the location of lesion. (Korean J Gastroenterol 2009;54:384-389)

Key Words: Malignant colorectal obstruction; Stent; Location

접수: 2009년 2월 27일, 승인: 2009년 6월 18일

연락처: 이광재, 443-721, 경기도 수원시 영통구 원천동 산 5 번지

아주대학교병원 소화기내과

Tel: (031) 219-6936, Fax: (031) 219-5999

E-mail: kjleemd@hotmail.com
Correspondence to: Kwang Jae Lee, M.D.

Department of Gastroenterology, Ajou University Hospital, San 5, Woncheon-dong, Yeongtong-gu, Suwon 443-721, Korea Tel: +82-31-219-6936, Fax: +82-31-219-5999

E-mail: kjleemd@ hotmail.com 


\section{서 론}

결장암은 서구화된 식생활, 동물성 지방의 과다 섭취 및 식물성 섬유소 섭취감소 등의 요인으로 인해서 우리나라에 서도 최근에 발생이 급격히 증가하고 있다. 증상이 있어서 진단된 경우에는 대개 진행성 병변으로 발견되며, 결장암 환자의 7-29\%에서 암에 의한 장 폐쇄가 발생한다. ${ }^{1,2}$ 결장 및 직장암에서 장 폐쇄가 발생하면 장이 확장되고 대변이 근위부 장에 남아 있으며 장 폐색으로 인해 전신상태가 불 량해진 경우가 많아서 응급절제술을 시행하게 되면 수술 후 사망률 및 이환율이 높아진다. ${ }^{3}$ 따라서 응급 장 절제술 대신 에 응급 결장 창냄술을 시행한 후에 단계적 장 절제술을 선 호한다. 그렇지만 단계적 장 절제술은 두 차례의 개복 수술 이 필요하고, 입원기간이 긴 단점이 있다. 이런 문제점을 보 완하기 위해서 최근에는 수술 전에 자가팽창형 스텐트 삽입 을 통해서 장 폐쇄를 해결함으로써 수술 전에 장세척을 할 수 있고, 환자의 전신상태를 호전시킬 수 있으며 수술 전 검 사를 충분히 할 수 있는 시간적 여유를 가질 수 있게 되어 서 응급 장 절제술 혹은 단계적 장 절제술 대신에 점차 사 용이 늘고 있다.

수술 전 스텐트 삽입은 주로 원위부에서 시행되고 있으나 이제는 스텐트 삽입 장비와 기술의 발달로 위치에 상관없이 대장 및 직장의 악성 폐쇄 치료에 이용될 수 있다. 결장암의 합병증으로 나타나는 장 폐쇄는 근위부 결장의 경우에는 일 반적으로 폐쇄의 정도가 원위부에 비해 심하지 않고, 축적 되는 대변의 양도 많지 않아서 수술 전에 스텐트를 응급으 로 삽입하지 않고 단단계 절제 및 문합을 하여도 비교적 안 전하다. 그렇지만 원위부 결장의 폐쇄로 증상이 있는 경우 에는 일반적으로 축적된 대변의 양이 많아서 수술 전에 장 폐쇄를 해결하지 못하면 다단계 수술을 시행해야 한다. 실 제로 근위부 장에 대한 수술 전 스텐트 삽입에 대해서는 아 직 유용성이 불확실하다. ${ }^{4-8}$ 스텐트 삽입 후에 장 폐쇄로 인 한 문제들이 성공적으로 해결되면 폐쇄 부위가 원위부여서 축적된 대변의 양이 많고, 장의 확장이 심한 경우에도 병변 이 보다 근위부에 있어서 축적된 대변의 양이 적은 경우와 비교해서 단단계 근치적 절제술의 결과에 차이가 없을 것으 로 보이며 스텐트 삽입으로 장 폐쇄가 효과적으로 해결이 되지 못하면 수술 결과가 폐쇄 병변의 위치에 따라서 달라 질 수 있을 것으로 추정된다. 그렇지만 이에 대한 연구는 아 직 보고된 바가 없다. 이에 저자들은 수술 전 폐쇄성 대장암 및 직장암에 대한 자가팽창형 금속 스텐트 삽입 후의 임상 적인 호전 여부 및 단단계 절제술을 시도한 경우의 수술 결 과를 장 폐쇄의 위치에 따라서 비교해 보고자 하였다.

\section{대상 및 방법}

\section{1. 대상}

2000년 5월부터 2008년 4월까지 아주대학교병원에서 폐 쇄성 결장 및 직장암으로 수술 전에 자가팽창형 금속 스텐 트 삽입을 시행 받고, 수술 절제가 가능하였던 57명의 환자 를 대상으로 이들의 의무기록을 후향 분석하였다. 이들은 시술 전 전산화단층촬영을 시행하여 원격전이가 없이 수술 로 근치 치료가 가능하다고 판단되었던 환자들이었다. 내원 당시에 장 폐쇄로 인한 복통, 복부 팽만, 변비 등의 증상이 있었고, 단순 복부 촬영 및 전산화단층촬영에서 병변 근위 부의 의미 있는 확장 소견이 관찰되었다. 조직검사는 스텐 트 삽입 전에 일반 대장 내시경으로 시행하거나 스텐트 삽입 을 할 당시에 같이 시행하였다. 이번 연구는 아주대병원 의 학연구윤리심의위원회(Institutional Review Board)의 심의를 통과하였다.

\section{2. 방법}

방사선 투시 하에 채널이 두 개인 내시경(GIF-2T200, Olympus, Co., Japan)을 병변 부위까지 삽입하고 폐쇄 부위 로 0.035 인치의 유도선(Zebra, Microvasive, USA)을 통과시 킨다. 협착의 길이를 알고 있는 경우에는 유도선을 따라 바 로 스텐트를 병변 부위에 위치시키지만 협착의 길이를 알 수 없는 경우에는 유도관을 유도선을 통해 삽입한 후에 조 영제를 주입하여 병변의 길이를 평가한 후, 다시 유도선으 로 바꾸어서 스텐트 전달 기구를 유도선을 따라 삽입하여 병변 부위에 위치시켰다. 방사선 투시 하에 스텐트 전달기 구의 바깥 막을 잡아당기면서 스텐트를 전달기구에서 이탈 시키면서 팽창시키고, 스텐트가 전달기구에서 다 이탈이 된 후에 유도선과 스텐트 전달기구를 제거하였다. 스텐트가 잘 위치되었는지를 확인하고, 단순 복부 촬영을 시행하여 합병 증 발생 여부를 확인하였다. 그 후 매일 장 폐쇄의 호전 유 무를 복통, 복부팽만, 배변횟수의 평가 및 단순 복부 촬영을 통해서 확인하였다. 장 폐쇄가 개선된 것으로 판단되면 미 음이나 유동식을 시작하였고 수술 전에 장정결제를 사용하 여 대장 세척을 한 후, 계획된 수술을 시행하였다.

병변의 위치에 따라 구불창자보다 근위부 장(A군), 구불 창자(B군), 직장(C군)의 세 부분으로 분류하여 각각에 대하 여 스텐트 삽입 후의 임상 호전 여부, 단단계 절제술률, 중 환자실 입원 유무와 기간, 수술 후 재원기간, 수술 후 합병 증 및 병원 내 사망률을 비교하였다. 스텐트 삽입이 기술적 으로 성공한 환자들만을 분석 대상으로 하였으며 임상적인 유효성은 환자가 대변을 보고 대장 폐쇄와 관련된 증상들이 호전되는 경우에 유효하다고 판정하였다. 


\section{3. 통계분석}

연속변수는 One-way ANOVA, Student's $t$-test, 범주형 변 수는 chi-square test와 Fisher's exact test를 사용하여 비교하 였고, 통계분석은 SPSS Window 12.0 (SPSS Inc., Chicago, $\mathrm{IL}, \mathrm{USA}$ )를 이용하였다. p값이 0.05 미만일 때 의미가 있다 고 판단하였다.

\section{결 과}

\section{1. 수술 전 스텐트 삽입군의 임상 특징}

결장 및 직장암으로 인한 장 폐쇄로 스텐트를 삽입하고, 근치 장절제술을 시행받은 환자는 총 57 명이었다. 병변의 위치에 의한 분류에서 $\mathrm{A}$ 군 13 명, B군 22 명, $\mathrm{C}$ 군 22 명이었 다. 평균연령은 64세(범위 23-85세)였고, 남녀비는 34:23이었 다. 연령 및 남녀비에 유의한 차이가 없었고, 당뇨, 고혈압, 만성 폐쇄성 폐질환, 간경화, 갑상선 기능저하증 등 전신적 으로 영향을 줄 수 있는 동반질환의 유병률도 각 군 간에
유의한 차이가 없었다. 비피막형(uncovered) 스텐트를 시술 받은 환자는 38 명이었고, 피막형(covered) 스텐트를 시술 받 은 환자는 19명이었으며, 비피막형과 피막형 스텐트의 선택 은 시술자의 판단에 의존하였고, $\mathrm{A}, \mathrm{B}, \mathrm{C}$ 군 간에 비피막형 과 피막형의 비율에 유의한 차이는 없었다(Table 1).

\section{2. 스텐트 삽입 후의 결과}

57명 중 52명에서 임상적인 유효성을 보였고, 5명은 스텐 트 삽입 후에도 대변을 못 보거나 폐쇄 증상이 호전되지 않 았다. 증상에 호전이 없었던 5명 중 C군이 3예, $\mathrm{A}$ 군이 2예 이고, 세 군 간에 스텐트의 임상적인 유효성에 통계적으로 유의한 차이는 없었다. 임상적인 유효성을 보이지 않은 5명 중 $\mathrm{A}$ 군 1 예만 단단계 절제술을 시행하였고, 나머지는 다단 계 수술을 시행하였다. 단단계 절제술률은 $\mathrm{A}$ 군 $92 \%, \mathrm{~B}$ 군 $100 \%, \mathrm{C}$ 군 $82 \%$ 로 C군에서 낮았으나 통계적인 유의성은 없 었다.

스텐트 관련 합병증은 스텐트 이탈이 $\mathrm{A}$ 군 2 명, $\mathrm{B}$ 군 1 명, $\mathrm{C}$ 군 1 명으로 각 군 간에 통계적으로 유의한 차이는 없었다. 장 천공은 $\mathrm{C}$ 군 1 명에서 발생하였다. 수술 후 합병증은 $\mathrm{A}$ 군

Table 1. Baseline Characteristics of Patients

\begin{tabular}{|c|c|c|c|c|c|}
\hline $\begin{array}{l}\text { Location of } \\
\text { obstruction }\end{array}$ & $\begin{array}{l}\text { Proximal to sigmoid } \\
\text { colon }(n=13)\end{array}$ & $\begin{array}{l}\text { Sigmoid colon } \\
\quad(n=22)\end{array}$ & $\begin{array}{l}\text { Rectum } \\
(\mathrm{n}=22)\end{array}$ & Total & p-value \\
\hline Age (range, years) & $67.8(39-85)$ & $62.5(39-79)$ & $61.6(23-77)$ & $63.6(23-85)$ & 0.171 \\
\hline Sex & & & & & 0.581 \\
\hline Male & 7 & 15 & 12 & 34 & \\
\hline Female & 6 & 7 & 10 & 23 & \\
\hline Comorbidity* & 7 & 7 & 6 & 20 & 0.560 \\
\hline \multicolumn{6}{|l|}{ Stent type } \\
\hline Covered & 6 & 4 & 9 & 19 & 0.149 \\
\hline Uncovered & 7 & 18 & 13 & 38 & \\
\hline
\end{tabular}

* DM, hypertension, chronic obstructive pulmonary disease, liver cirrhosis, hypothyroidism.

Table 2. Clinical Improvement Rates and Operative Results after Stent Insertion

\begin{tabular}{|c|c|c|c|c|c|}
\hline & $\begin{array}{l}\text { Proximal to } \\
\text { sigmoid colon }(n=13)\end{array}$ & $\begin{array}{l}\text { Sigmoid colon } \\
\quad(n=22)\end{array}$ & $\begin{array}{l}\text { Rectum } \\
(\mathrm{n}=22)\end{array}$ & $\begin{array}{l}\text { Total } \\
(\mathrm{n}=57)\end{array}$ & p-value \\
\hline Clinical improvement & $11(85 \%)$ & $22(100 \%)$ & $19(86 \%)$ & $52(91 \%)$ & 0.176 \\
\hline One-stage resection & $12(92 \%)$ & $22(100 \%)$ & $18(82 \%)$ & $52(91 \%)$ & 0.102 \\
\hline Stent-related complications & & & & & 0.638 \\
\hline Perforation & 0 & 0 & $1(5 \%)$ & $1(2 \%)$ & 0.445 \\
\hline Migration & $2(15 \%)$ & $1(5 \%)$ & $1(5 \%)$ & $4(7 \%)$ & 0.405 \\
\hline Post-op complications & $1(8 \%)$ & $3(14 \%)$ & $4(18 \%)$ & $8(14 \%)$ & 0.687 \\
\hline ICU care & $3(23 \%)$ & $3(14 \%)$ & $6(27 \%)$ & $12(21 \%)$ & 0.529 \\
\hline ICU stay (mean (range) days) & $4.0(3-5)$ & $4.0(3-6)$ & $10.5(4-25)$ & $7.3(3-25)$ & 0.269 \\
\hline Post-op hospital stay (mean (range) days) & $16.2(11-23)$ & $14.5(8-31)$ & $18.5(9-71)$ & $16.5(8-71)$ & 0.331 \\
\hline In-hospital mortality & 0 & 0 & $1(5 \%)$ & $1(2 \%)$ & 0.456 \\
\hline
\end{tabular}

ICU, intensive care unit. 
에서 창상감염 1 명 $(8 \%), \mathrm{B}$ 군에서 폐부종, 문합부 누출, 수술 후 출혈로 3 명 $(14 \%)$ 에서 합병증이 있었고, $\mathrm{C}$ 군에서는 폐렴 1 명, 창상감염 1명, 수술 후 출혈 2명으로 총 4명(18\%)에서 합병증이 발생하였으며 세 군 간에 통계적으로 유의한 차이 는 없었다. C군 중 수술 후 폐렴이 발생하였던 1명은 호흡 곤란 증후군으로 사망하였다. 수술 후 중환자실에 입원한 환자들은 A군 3명, B군 3명, $\mathrm{C}$ 군 6명으로 통계적으로 유의 한 차이는 없었으며 중환자실의 평균 재원기간도 $\mathrm{A}$ 군 4 일, $\mathrm{B}$ 군 4 일, $\mathrm{C}$ 군 10.5 일로 세 군 간에 유의한 차이는 없었다. 수술 후 평균 재원기간은 A군 16.2 일, B군 14.5 일, C군 18.5 일로 의미 있는 차이를 보이지 않았다(Table 2).

\section{고 찰}

장 폐쇄는 대장 및 직장암 환자들의 약 7-29\%에서 초기 증상으로 나타날 수 있는 흔한 합병증이다. ${ }^{1,2}$ 대장 및 직장 암에 동반된 대장 및 직장의 폐쇄는 응급 수술이 필요하기 때문에 수술 전 전신 상태 및 영양 상태를 충분히 교정하고 시행하는 계획된 수술에 비해 사망률과 이환율이 높을 수 밖에 없다. ${ }^{3}$ 따라서 대장암에 의한 폐쇄는 응급 결장 창냄술 을 먼저 시행하고, 나중에 2 단계로 대장암에 대한 근치 절 제를 시행하는 수술이 시행되어 왔다. 그러나 1991년에 Dohmoto'이 폐쇄성 직장암에 처음으로 증상 완화 목적으로 스텐트를 삽입한 증례를 보고하였고, Tejero 등 ${ }^{10}$ 이 수술 전 에 대장 및 직장암 폐쇄에 대한 스텐트 삽입술을 소개한 이 후로 최근에는 수술 전 장 폐쇄의 치료에 스텐트 삽입이 우 선적으로 시행되는 경우가 증가하고 있다.

수술 전에 스텐트 삽입이 응급 결장 창냄술과 비교하여 효과적이라고 보고되고 있지만, ${ }^{11}$ 대부분의 스텐트 삽입은 구불창자와 직장과 같은 원위부 대장에서 시행되었다. ${ }^{12}$ 그 이상의 근위부 대장의 폐쇄는 대변의 축적이 상대적으로 적 기 때문에 결장 창냄술 시행 후에 근치 수술을 시행하는 다 단계 수술을 하지 않고, 바로 병변을 절제하고 회장 대장 문 합술을 하는 단단계 수술을 일반적으로 시행하였다. ${ }^{13-15}$ 또 한 과거에는 스텐트가 주로 식도 병변을 치료하기 위해 고 안되었기 때문에 스텐트 삽입기구의 길이가 길지 않고, 내 시경의 겸자공을 통한 스텐트 삽입이 불가능하여 원위부 대 장의 병변에만 한정되었다. ${ }^{6}$ 그러나 단단계 수술도 응급 수 술이기 때문에 계획된 수술에 비해서는 사망률과 이환율이 높다. ${ }^{16,17}$ 스텐트 삽입의 기구가 길어지고, 내시경의 겸자공 를 통한 삽입이 가능해지면서 대장암 폐쇄의 치료를 위한 스텐트 삽입도 발전하여서 Campbell 등은 횡행결장에 처음 스텐트를 삽입한 증례를 보고하였고, 이후에는 위치에 관계 없이 근위부 대장에도 스텐트를 삽입하여 장 폐쇄를 치료하 였다는 보고들이 있어 왔다. ${ }^{7.8}$ 즉 기구 및 기술의 발전으로
폐쇄 부위에 상관없이 스텐트 삽입이 가능하게 되었다.

장 폐쇄를 유발하는 암을 가진 환자들은 대개 고령이거 나, 암이 상당히 진행된 경우가 많다. 우측 장이 막힌 경우 에는 대개 단단계로 절제하고 문합을 하는 것이 가능하지만 좌측 장이 막힌 경우에는 단단계로 절제와 문합술을 하는 것이 사망률과 이환율을 증가시킬 수가 있다. 즉 폐쇄의 부 위에 따라서 수술의 결과가 달라질 수 있으며, 이는 폐쇄의 정도가 우측 장에 비해 좌측 장이 더 심한 경우가 많고, 대 변의 축적이 원위부 폐쇄일수록 많아지기 때문으로 추정된 다. 따라서 수술 전에 스텐트 삽입을 하는 경우에 스텐트 삽 입이 폐쇄를 효과적으로 치료하였으면 부위에 따른 수술 결 과의 차이는 적을 것으로 판단된다. 지금까지의 대장 및 직 장의 악성 폐쇄의 스텐트 삽입 치료에 대한 연구들은 삽입 의 성공률 및 성적, 수술과의 비용효과적인 비교에 관한 것 이 많았으며 폐쇄 부위에 따른 임상 호전율 및 단단계 근치 절제술을 시도하였을 때의 수술 결과를 비교한 연구는 거의 없었다. 이번 연구에서는 스텐트를 성공적으로 폐쇄부위에 삽입한 경우에는 폐쇄로 인한 영향이 사라지기 때문에 결국 폐쇄의 위치나 정도에 상관없이 수술의 결과는 비슷해진다 는 소견을 입증해주고 있다.

이번 연구에서는 대장암의 병변 위치에 따라 구불창자보 다 근위부, 구불창자, 직장의 세 군으로 구분하여 각각의 군 에서 절제가 가능하고 수술 전에 스텐트 삽입이 성공하였던 증례들만을 모아서 임상 호전율, 스텐트 관련 합병증, 단단 계 절제술률, 수술 후 합병증, 중환자실 치료 여부 및 중환 자실 재원기간, 수술 후 재원기간, 입원기간 중 사망률 등을 비교해 보았다. 이와 같은 비교를 통해서 암성 장 폐쇄로 내 원한 환자들이 수술 전에 스텐트 삽입을 하게 되면 병변의 위치에 상관없이 결과가 좋을 것인지, 아니면 수술에서와 같이 폐쇄의 위치에 따라서 단단계 절제율 및 수술 후의 결 과가 다를 것인지를 알고자 하였다. 스텐트 삽입의 전체적 인 기술적 성공률은 약 $75-100 \%$ 로 보고되고 있으나 ${ }^{18}$ 이번 연구에서는 삽입 성공률은 언급하지 않았다. 일반적으로 전 향 연구가 아닌 경우에는 내시경이 병변에 도달하지 못하거 나 병변에 도달한 경우에도 유도관의 삽입이 실패한 경우에 기록에 남기지 않고 바로 수술 치료로 넘어가는 경우가 흔 해서 후향 연구에서는 실제보다 삽입의 성공률이 과장될 수 있다. 따라서 이번 연구의 경우에는 후향으로 의무기록을 검토하였기 때문에 스텐트 삽입의 성공률은 결과에 포함시 키지 않았다. 일반적으로 기술적인 면에서 병변의 위치가 근위부일수록 스텐트 삽입이 더 어렵다고 볼 수는 없으며, 스텐트 삽입 실패의 주 원인은 내시경이 병변에 도달하지 못하는 경우보다 병변 부위의 협착이 심하거나 병변이 길게 구불구불 꼬여 있어 유도선을 완전히 통과시킬 수 없는 경 우가 더 흔하여서 ${ }^{5,18}$ 병변의 위치보다는 병변의 형태가 더 
중요한 것으로 보인다. 그 외에 스텐트가 성공적으로 삽입 이 된 경우에도 병변의 협착 부위가 너무 압력이 강해서 스 텐트가 완전히 펴지지 않는 경우에는 스텐트가 제 기능을 하지 못할 수도 있다. 실제로 스텐트 삽입 후의 임상적 호전 율은 약 $84-100 \%$ 로 보고되어 있으며 ${ }^{18}$ 이번 연구에서는 전 체적으로 $91 \%$ 였고, 병변의 위치에 따른 통계적인 차이를 발견할 수 없었다. 임상적으로 호전되지 않는 경우는 정체 된 대변으로 인해 내강이 막히거나 병변의 길이에 비해 적 절치 못한 스텐트를 사용했을 때에 나타날 수 있다. ${ }^{19}$

합병증으로 장 천공, 스텐트 이틸, 재폐쇄, 출혈 등이 나 타날 수 있다. 그 중에서도 가장 심각한 합병증인 장 천공은 약 $4 \%$ 로 보고되고 있으며 ${ }^{11}$ 이번 연구에서도 직장군 중 1 예 에서 발생하여 응급수술로 병변을 제거하고, 결장 창냄술을 시행하였다. 장 천공과 연관된 위험 인자로 여러 연구들에 서 스텐트 삽입 전 병변의 풍선 확장술을 언급하였다. ${ }^{5,11,20,21}$ 스텐트 이탈은 구불창자보다 근위부군에서 2예, 구불창자군 에서 1 예, 직장군에서 1 예로 4 명의 환자에서 관찰되었는데 3 명은 다시 스텐트를 삽입하였고, 1 명은 스텐트가 이탈한 후에도 증상이 호전되고 대변을 볼 수 있어서 스텐트 재삽 입 없이도 근치 절제술을 시행할 수 있었다. 일반적으로 짧 은 스텐트 길이, 피막형 스텐트, 양성병변이나 대장 외 병변 에 의한 협착, 국소 방사선치료를 한 경우 등이 스텐트 이탈 과 관련된 인자들로 추정되고 있다. 스텐트 삽입술과 관련 된 의미 있는 출혈은 이번 증례들에서는 발생하지 않았다. 단단계 수술률의 경우에 가장 원위부인 $\mathrm{C}$ 군에서 상대적 으로 낮았으나 통계적으로 유의한 차이는 아니었다. 수술 후 합병증 발생, 중환자실 입원 유무, 중환자실 입원 기간 등에서도 각 부위에 따른 차이를 보이지 않았다. 이는 병변 이 원위부일수록 근위부 병변인 군에 비해 폐쇄된 대장 길 이가 길고, 축적된 대변의 양이 많아서 감압이나 대장 정결 면에서 불리할 가능성이 많지만 수술 전에 스텐트 삽입을 통해서 이러한 단점을 극복할 수 있음을 보여주고 있다. 스 텐트 삽입은 결장 창냄술에 비해 응급수술을 피할 수 있다 는 장점뿐만 아니라 환자의 정신 신체적인 면이나 삶의 질 적인 측면, 경제적인 면에서도 이득이 있다. ${ }^{22,23}$ 근위부 폐쇄 성 대장암 환자는 원위부 대장암과 달리 폐쇄가 심하지 않 고, 대변의 축적이 적기 때문에 단단계 수술을 시행하는 경 우가 많아서 다단계 수술을 피하기 위해 수술 전에 스텐트 를 삽입하는 경우가 많지 않다. 이번 연구에서도 하행결장 보다 근위부에 폐쇄 병변이 있어서 수술 전에 스텐트를 삽 입한 경우는 4예로 상대적으로 매우 적었다. 그렇지만 폐쇄 로 인한 증상 및 징후가 심한 경우에는 계획된 수술에 비하 여 응급 수술에 따르는 위험이 존재하기 때문에 응급 수술 을 피하기 위한 수술 전 스텐트 삽입술을 적극적으로 고려 해 볼 필요가 있다. 향후 근위부 결장에 폐쇄가 있는 경우에
수술 전에 스텐트 삽입을 하고 계획된 근치 절제술을 하는 경우와 응급으로 단단계 절제술을 하는 경우의 수술 결과 및 효율성을 비교한 연구가 필요할 것으로 보인다.

결론으로 이번 연구에서는 대장 및 직장의 악성 폐쇄에 대하여 수술 전에 스텐트 삽입을 성공적으로 한 경우에는 병변의 위치에 상관없이 임상적인 호전율과 단단계 절제술 의 수술 결과가 비슷하였고, 이런 결과는 스텐트 삽입을 통 해서 장 폐쇄가 해결이 되면 폐쇄의 부위에 의한 영향을 최 소화할 수 있음을 의미한다. 이번 연구는 후향 의무기록을 통해서 분석된 제한점이 있기 때문에 향후 무작위 전향 대 규모 연구가 필요할 것으로 보인다.

\section{요 약}

목적: 대장 및 직장암의 합병증으로 나타나는 장 폐쇄는 근위부 결장의 경우에는 단단계 절제 및 문합이 비교적 안 전하지만 원위부 결장의 경우에는 축적된 대변의 양이 많아 서 수술 전에 장폐쇄 및 장정결을 해결하지 못하면 다단계 수술을 시행해야 한다. 장 폐쇄는 원위부 결장에서 호발하 기 때문에 스텐트 삽입도 주로 직장 및 구불창자에서 시행 되어 왔으나 장비 및 기술의 발달로 위치에 상관없이 스텐 트 삽입이 가능하게 되었다. 이에 저자들은 수술 전 폐쇄성 대장암 및 직장암으로 스텐트를 성공적으로 삽입한 환자를 대상으로 병변의 위치에 따라서 스텐트 삽입술의 효과 및 단단계 절제술의 결과에 미치는 영향을 비교해 보고자 하였 다. 대상 및 방법: 2000년 5월부터 2008년 4월까지 아주대 학교병원에서 폐쇄성 결장 및 직장암으로 수술 전에 자가팽 창형 금속 스텐트 삽입을 시행 받고, 수술로 근치 절제를 시 행하였던 57 명의 환자를 대상으로 이들의 의무기록을 후향 분석하였다. 병변의 위치에 따라 구불창자보다 근위부 장(A 군), 구불창자(B군), 직장(C군)의 세 부분으로 분류하여 각 각에 대하여 스텐트 삽입 후의 임상적인 호전 여부, 단단계 절제술률, 중환자실 입원 유무와 기간, 수술 후 재원기간, 수술 후 합병증 및 병원 내 사망률을 비교하였다. 결과: 병 변의 위치에 의한 분류에서 $\mathrm{A}$ 군 13 명, B군 22 명, $\mathrm{C}$ 군 22 명 이었다. 연령, 남녀비, 전신적으로 영향을 줄 수 있는 동반 질환의 유병률, 스텐트의 종류는 A, B, C군 간에 유의한 차 이는 없었다. 세 군 간에 스텐트 관련 합병증, 임상적인 유 효성 및 단단계 절제술률에 유의한 차이는 없었다. 수술 후 합병증, 수술 후 중환자실 입원율, 중환자실 평균 재원기간, 수술 후 재원기간, 병원 내 사망률도 세 군 간에 유의한 차 이가 없었다. 결론: 수술 전에 폐쇄성 대장암 및 직장암으 로 스텐트를 삽입하고, 단단계 근치 절제술을 시행 받은 환 자들은 스텐트 삽입술의 임상적인 효과 및 수술의 결과가 병변의 위치에 따라 차이가 나지 않았다. 따라서 수술 전 스 
텐트 삽입술은 폐쇄성 대장암 및 직장암에서 단단계 근치 절제술을 시행하는 데 병변의 위치에 상관없이 유효할 것으 로 판단된다.

색인단어: 폐쇄성 대장직장암, 스텐트, 위치

\section{참고문헌}

1. Regland JJ, Londe AM, Spratt JS. Correlation of the prognosis of obstructing colorectal carcinoma with clinical and pathologic variables. Am J Surg 1971;121:552-556.

2. Mauro MA, Koehler RE, Baron TH. Advances in gastrointestinal intervention: the treatment of gastroduodenal and colorectal obstructions with metallic stent. Radiology 2000;215: 659-669.

3. Barillari P, Aurello P, de Angelis R, et al. Management and survival of patients affected with obstructive colorectal cancer. Int Surg 1992;77:251-255.

4. Bhardwaj R, Parker MC. Palliative therapy of colorectal carcinoma: stent or surgery? Colorectal Dis 2003;5:518-521.

5. Camúñez F, Echenagusia A, Simó G, Turégano F, Vázquez J, Barreiro-Meiro I. Malignant colorectal obstruction treated by means of self-expanding metallic stents: effectiveness before surgery and in palliation. Radiology 2000;216:492-497.

6. Campbell KL, Hussey JK, Eremin O. Expandable metal stent application in obstructing carcinoma of the proximal colon: report of a case. Dis Colon Rectum 1997;40:1391-1393.

7. Shim CS, Cho JY, Jung IS, et al. Through-the-scope double colonic stenting in the management of inoperable proximal malignant colonic obstruction: a pilot study. Endoscopy 2004;36:426-431.

8. Alessandro R, Douglas GA, Christopher MG, Alberto M, Paoletta P, Todd HB. Stenting of the proximal colon in patients with malignant large bowel obstruction: techniques and outcomes. Gastointest Endosc 2007;66:940-944.

9. Dohmoto M. New method-endoscopic implantation of rectal stent in palliative treatment of malignant stenosis. Endoscopia Digestiva 1991;3:1507-1512.

10. Tejero E, Mainar A, Fernandez L, Tobio R, De Gregorio MA. New procedure for the treatment of colorectal neoplastic obstructions. Dis Colon Rectum 1994;37:1158-1159.
11. Khot UP, Lang AW, Murali K, et al. Systematic review of the efficacy and safety of colorectal stent. Br J Surg 2002; 89:1096-1102.

12. Lo SK. Metallic stenting for colorectal obstruction. Gastrointest Endosc Clin N Am 1999;9:459-477.

13. Fielding LP, Stewart-Brown S, Blesovsky L. Large bowel obstruction caused by cancer: a prospective study. $\mathrm{Br}$ Med J 1979;ii:515-517.

14. Phillips RKS, Hittinger R, Fry JS, Fielding LP. Malignant large bowel obstruction. Br J Surg 1985;72:296-302.

15. Buechter KJ, Boustany $\mathrm{CH}$, Caillouette R, Cohn I. Surgical management of the acutely obstructed colon. Am J Surg 1988;156:163-168.

16. Hsu TC. Comparison of one-stage resection and anastomosis of acute complete obstruction of left and right colon. Am J Surg 2005;189:384-387.

17. Lee YM, Law WL, Chu KW, et al. Emergency surgery for obstruction colorectal cancers: a comparison between rightsided and left-sided lesions. J Am Coll Surg 2001;192:719725.

18. Keymling M. Colorectal stenting. Endoscopy 2003;35:234238.

19. Harris GJ, Senagore AJ, Lavery IC, Fazio VW. The management of neoplastic colorectal obstruction with colonic endoluminal stenting devices. Am J Surg 2001;181:499-506.

20. Diaz LP, Pabon IP, Lobato RF, et al. Palliative treatment of malignant colorectal strictures with metallic stents. Cardiovasc Intervent Radiol 1999;22:29-36.

21. Saida Y, Smiyama Y, Nagao J, et al. Stent endoprosthesis for obstructing colorectal cancers. Dis Colon Rectum 1996;39: 552-555.

22. Tomiki Y, Watanabe T, Ishibiki Y, et al. Comparison of stent placement and colostomy as palliative treatment for inoperable malignant colorectal obstruction. Surg Endosc 2004; 18:1572-1577.

23. Binkert CA, Ledermann H, Jost R, Saurenmann P, Decurtins M, Zollikofer CL. Acute colonic obstruction: clinical aspects and cost-effectiveness of preoperative and palliative treatment with self-expanding metallic stents--a preliminary report. Radiology 1998;206:199-204. 